Vol. 23, No. 2, pp. 178 183, 2020.

\title{
Recent progress in silicon photocatalyst
}

\author{
Min Woo Lee ${ }^{1}$, Woo Young Shim ${ }^{1 \dagger}$ \\ 'Department of Materials Science and Engineering, Yonsei University, Seoul, \\ 03722, Republic of Korea
}

\section{실리콘 광 촉매 연구동향}

\author{
이민우 ${ }^{1}$, 심우영 ${ }^{1 \dagger}$ \\ ${ }^{1}$ 연세대학교 신소재공학과
}

(Received June 3, 2020; Accepted June 19, 2020)

\begin{abstract}
Solar energy conversion is now actively researching because of pollution. Especially silicon photocatalyst has big potential, because of wide absorption range. But low quantum yield of silicon photocatalyst can't be used for commercialization. This paper summarize mechanism of silicon photocatalyst. In addition, properties and current states of photo catalyst using nanomaterials of silicon are also introduced.
\end{abstract}

Keywords: Silicon, photocatalyst, nanomaterials, Hydrogen evolution, water splitting

\section{1. 서론}

최근 수십년간 산업의 발전으로 인한 에너지수요가 증가함에 따라 대체 에너지원의 필요성이 부각되고 있 다. 그 중 태양광에너지는 환경오염을 동반하지 않는 청 정에너지이라는 점과 한정되지 않은 에너지원이라는 점 에서 많은 연구가 진행되고 있다. 태양광은 반도체 물 질에 빛을 가하였을 때 생기는 전자와 정공을 이용하는 방법으로 에너지 활용을 할 수 있다. 여러 활용방법 중
광 촉매는 태양광을 이용하여 주로 물을 분해해 또 다 른 청정에너지원인 수소를 발생하거나 환경 오염 물질 을 분해하는 용도로 사용된다. Fig. 1 (a)에서 보듯 광 합성이 빛을 이용해 물과 이산화 탄소를 녹말로 만드 는 것처럼 광 촉매의 경우 같은 물질로 산소, 수소, 유 기화합물들을 생성할 수 있기 때문에 인공 광합성이라 고도 불린다. 광 촉매의 기본 원리는 빛으로 생성된 전 자가 물의 환원반응, 정공이 물의 산화반응을 유도하 여 물을 분해하는 산화환원 반응이다. 전자는 높은 에 
(a)

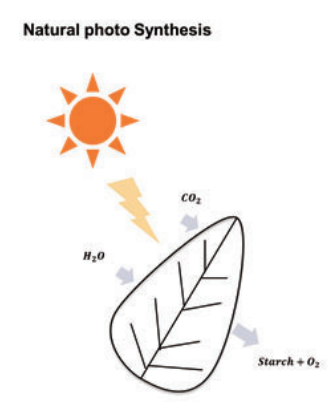

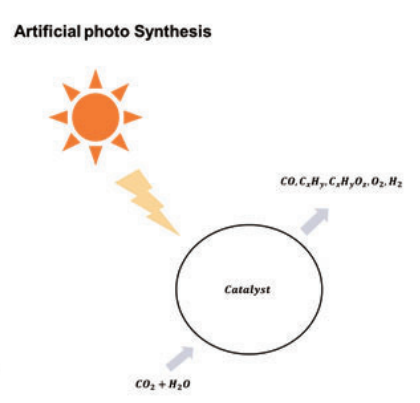

(b)

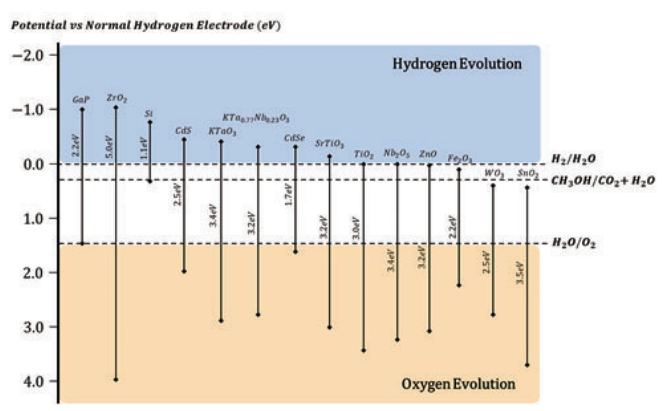

Fig. 1. 인공 광합성의 의미 및 광 촉매 후보군

너지에서 낮은 에너지로, 반대로 정공은 낮은 에너지 에서 높은 에너지로 거동하는 특성이 있는데 이런 특성 으로 일어나는 반응이 산화환원반응이다. 그리고 연구 에 따르면 반도체 내에서 생성된 전자는 물의 환원반응 을 유도하는 photocathode, 정공은 산화반응을 유도하 는 photoanode로 표현 할 수 있고 각각의 전기화학 포 텐셜은 $\Phi^{\mathrm{re}}$ (photocathode)와 $\Phi^{\mathrm{OX}}$ (photoanode)로 표현 가능하다. 또한 물의 환원 반응시 전자의 전기화학 포텐 셜은 $\Phi\left(\mathrm{H}^{+} / \mathrm{H}_{2}\right)$, 산화반응은 $\Phi\left(\mathrm{O}_{2} / \mathrm{H}_{2} \mathrm{O}\right)$ 로 표현가능하 고 각각의 환원전위와 대응된다고 알려져 있다. ${ }^{1}$ 따라서 전자 1 개의 깁스에너지가 전기화학 포텐셜로 표현되니 식 (1)을 만족해야 물 분해가 일어난다.

$\Phi^{\mathrm{OX}}-\Phi\left(\mathrm{H}^{+} / \mathrm{H}_{2}\right)>0, \Phi^{\mathrm{re}}-\Phi\left(\mathrm{O}_{2} / \mathrm{H}_{2} \mathrm{O}\right)<0$

이러한 이유로 재료 빛을 가했을 때 생성되는 전자와 정공 전위가 중요하다. 생성되는 전자의 전위가 전도대 의 가장 낮은 전위이고, 정공은 충만대의 가장 높은 에 너지로 표현할 수 있고 이를 Fig. 1 (b)에 표현했다. 전 도대의 가장 낮은 위치가 물의 환원반응의 전위보다 높 으면 수소발생이 가능하고, 충만대의 가장 높은 위치 가 물의 산화반응의 전위보다 낮으면 산소발생이 가능 하다. 한가지 조건만 부합할 경우 부합하지 않는 부분에 다른 반응을 유도하여 사용한다. 예를 들면 수소발생에 는 적합하지만 산소발생이 적합하지 않을 경우 반응용 매에 메탄올을 추가해 Fig. 1 (b)에 표현되었듯 생성된
정공이 메탄올의 산화반응을 유도해 전자와의 재결합을 막아준다.

재료의 밴드 갭이 모두 다르기 때문에 이용할 수 있는 태양광의 파장영역이 모두 다르게 된다. 가시광선은 매 우 좁은 파장영역을 가짐에도 불구하고 태양광에서 많 은 부분(44\%)을 차지한다. 따라서 밴드 갭이 작을수록 이용할 수 있는 태양광의 영역이 넓다. 이러한 이유로 빛을 흡수하는 다른 응용분야인 태양전지에서는 밴드 갭이 근 적외선 영역 $(1.1 \mathrm{eV})$ 임에 따라 가시광을 모두 흡 수할 수 있는 실리콘이 좋은 성능을 보인다. 따라서 이 러한 장점으로 실리콘을 이용한 광 촉매의 경우 엄청난 잠재성을 가지고 있다고 볼 수 있다. 본 논문에서는 이 러한 장점을 가진 실리콘을 이용한 광 촉매의 연구동향 과 앞으로의 발전방향에 대해 논해보고자 한다.

\section{2. 실리콘 나노 물질의 촉매특성}

표면에서 산화환원 반응을 알기 위해서는 실리콘 표면 에서의 전자 정공의 거동이 매우 중요하다. Science and Technology of China 대학의 Yujie Xiong연구팀은 최 근 실리콘 표면에서의 광화학적 물 분해 과정을 제일원리 계산을 통해 밝혀냈다 ${ }^{2)}$. Fig. 2 (a)는 실리콘 원자와 수소 원자가 붙은 작용기 $(\mathrm{Si}-\mathrm{H})$ 와 하이드록실기 $(-\mathrm{OH})$ 가 붙은 부분에서의 전자와 정공의 life time을 계산을 통해 모식 화 한 결과이다. 그림에서 볼 수 있듯 순수한 실리콘보다 작용기에서 전자와 정공모두 life time이 긴 것을 확인할 
수 있으며 실질적인 산화환원 반응은 작용기에서 일어난 다고 할 수 있다. 연구에 따르면 순수한 실리콘 원자한개 가 광 여기된 정공의 일부 $\left(0.03 \mathrm{~h}^{+}\right)$를 수용 가능하며 표면 에서의 물의 흡착을 크게 향상시킬 수 있다. 흡착된 물은 실리콘과 식 (2)의 반응을 하여 하이드록실기가 붙은 실 리콘과 $\mathrm{H}^{+}$을 생성한다. 생성된 $\mathrm{H}^{+}$는 두가지의 작용기가 붙은 부분에서 환원반응을 할 수 있다. 수소작용기의 경 우 식 (3)와 같이 수소작용기를 없애고 수소를 발생시키 는 반면, 하이드록실기는 식 (4)와 같이 반응 후 작용기를 없애고 물을 생성한다. 이러한 하이드록실기의 반응은 광 반응의 효율성을 저해하는 요인 중 하나로 작용한다. 마 지막으로 정공의 경우 식 (5)와 같이 하이드록실기와 반 응하여 산화된 실리콘과 $\mathrm{H}^{+}$을 생성하여 반응을 저해하는 반응이 된다. 즉 Fig. 2 (b)에 표현된 것 같이 생성된 전 자, 정공이 물과 직접적으로 반응하는 것이 아닌 서로 다 른 장소로 분리되어 작용기와의 반응으로 수소가 생성이 된다. 이러한 이유로 수소 작용기가 매우 중요하고 반응 이 진행됨에 따라 수소작용기가 하이드록실기로 대체되 어 광 효율이 점점 낮아지게 된다. 위 연구에서는 이를 해 결하기 위해 반응 후 불산을 사용해 표면 산화막을 제거 하고 수소 작용기를 생성시켜 다시 사용할 수 있다고 하 였다. 많은 실리콘 광 촉매의 실험에서는 앞서 언급한 것 과 같이 정공의 부가적인 반응을 막기위해 메탄올을 이 용한다. 그러나 실리콘은 물과 반응하여 식 (6), 식 (7)와 같이 산화막을 생성하거나 규산을 형성하여 수소가 발생 한다고 알려져 있다3). 또한 그로인한 표면산화로 반응할 수 있는 면적이 줄어든다고 알려져 있다). 이런 문제점 때 문에 실리콘은 빛을 가한 것과 가하지 않은 상태에서 모 두 수소가 발생하고 두 값의 차이로 광반응으로 인한 수 소 발생량을 확인한다.

$$
\begin{aligned}
& h^{+}+\mathrm{Si}+\mathrm{H}_{2} \mathrm{O}=\mathrm{Si}\left(h^{+}\right)-\mathrm{H}_{2} \mathrm{O}=\mathrm{Si}-\mathrm{OH}+H^{+} \\
& e^{-}+\mathrm{Si}-\mathrm{H}+H^{+}=\mathrm{Si}-\mathrm{H}\left(e^{-}\right)+H^{+}=\mathrm{Si}+\mathrm{H}_{2} \\
& e^{-}+\mathrm{Si}-\mathrm{OH}+H^{+}=\mathrm{Si}-\mathrm{OH}\left(e^{-}\right)+H^{+}=\mathrm{Si}+\mathrm{H}_{2} \mathrm{O} \\
& h^{+}+\mathrm{Si}-\mathrm{OH}+\mathrm{H}_{2} \mathrm{O}=\mathrm{Si}\left(h^{+}\right)-\mathrm{OH}=\mathrm{Si}-\mathrm{O}+H^{+} \\
& \mathrm{Si}+2 \mathrm{H}_{2} \mathrm{O}=\mathrm{SiO}_{2}+2 \mathrm{H}_{2} \\
& \mathrm{Si}+4 \mathrm{H}_{2} \mathrm{O}=\mathrm{Si}_{2}(\mathrm{OH})_{4}+2 \mathrm{H}_{2}
\end{aligned}
$$

(a)

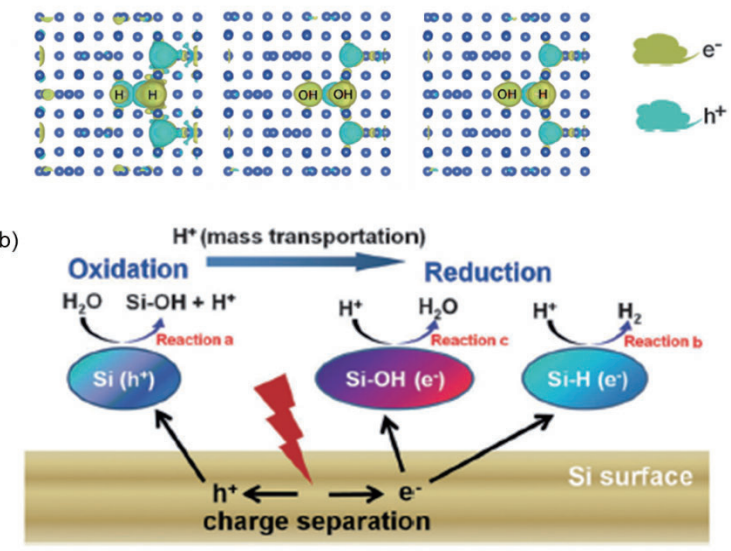

Fig. 2. 실리콘 광 촉매의 메커니즘

산화환원 반응은 표면에서 일어나는 반응이기 때문에 광 촉매의 효율은 반응면적과 직결되는 표면적과 매우 큰 관련이 있다. 따라서 모든 광 촉매는 표면적을 극대화 하기 위해 나노 물질의 재료를 사용한다. 따라서 실리콘 을 이용한 광 촉매도 나노 물질 형태로 사용한다. 나노 물질의 형태로 진행되어온 연구들을 0 차원, 1 차원, 2 차 원 3 부분으로 나누어 정리하고자 한다.

\subsection{0 차원 재료}

0 차원의 물질은 표면적의 증가를 위해 0 차원의 실리 콘을 이용한 연구는 다공성 물질의 나노 입자를 사용 하는 연구가 주를 이룬다. Pennsylvania 주립 대학의 Donghai Wang 연구팀은 Fig. 3 (a)와 같이 사염화탄소 를 환원하여 염을 제거하는 방식으로 다공성 실리콘 나 노 입자를 만드는데 성공하였다 ${ }^{4)}$. 입자의 크기는 5 20 $\mu \mathrm{m}$ 로 큰 편이지만 Fig. 3 (b)에서 볼 수 있듯 $\mathrm{BET}$ 분석 결과 기공 평균 직경이 약 $10 \mathrm{~nm}$ 로 분포되어 있는 다공 성 물질이고 $580 \mathrm{~m}^{2} / \mathrm{g}$ 의 높은 표면적을 가지고, 양자제 한효과로 광학적 밴드 갭이 $1.63 \mathrm{eV}$ 로 증가되었다고 발 표했다. 이러한 높은 표면적으로 인해 Fig. 3 (c)과 같이 평균 $882 \mu \mathrm{mol} /(\mathrm{g} \cdot \mathrm{hr})$ 의 높은 발생량을 나타났었고 지속 시간은 현재까지 중 가장 긴, 55 시간을 나타냈다. 또 다른 물질의 경우도 다공성의 나노 입자를 사용하였고, 이 경 우에는 실리카 입자를 뭉친 후 마그네슘 환원을 하는 방 
(a)

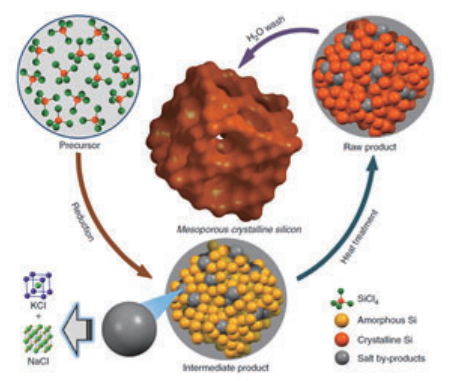

(d)

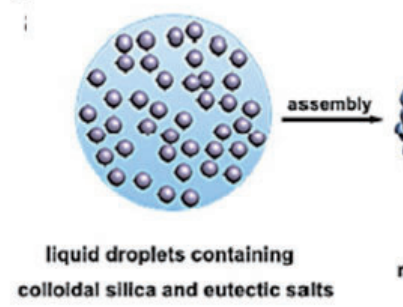

(b)

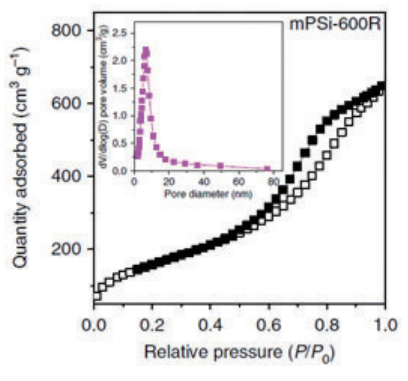

(c)

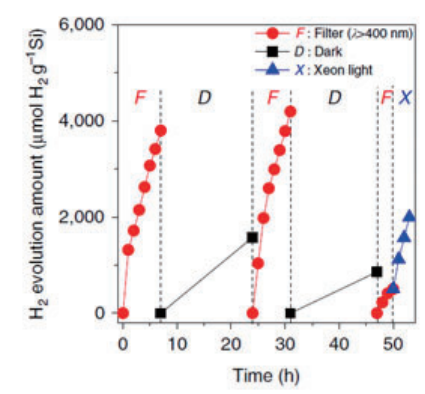

(e)

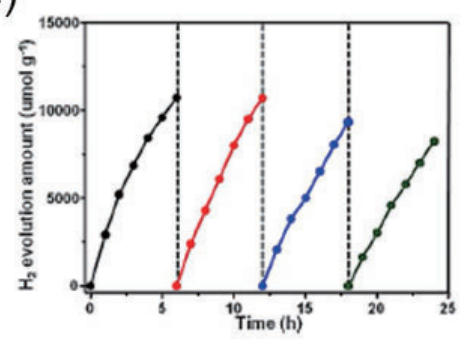

Fig. 3. 0차원 실리콘의 제조공정 및 수소발생 데이터

법을 이용하였다.5). Science and Technology of China 대학의 Yujie Xiong연구팀에서 만든 이 물질은 광학적 밴드 갭 $1.73 \mathrm{eV}$, 표면적 $337 \mathrm{~m}^{2} / \mathrm{g}$, 평균 기공 사이즈 $6.1 \mathrm{~nm}$ 인 것으로 분석이 되었다. 표면적이 위의 물질 보 다 낮지만 수소 발생량은 $1785 \mu \mathrm{mol} /(\mathrm{g} \cdot \mathrm{hr}$ )로 실리콘만 을 이용한 연구 중 가장 높은 값이 나왔다. 그 원인으로는 결정성이 위의 물질보다 좋은 것을 이유라고 보고되었다.

\subsection{1 차원 재료}

광 촉매로의 1 차원 실리콘은 대표적인 형태인 실리콘 나노 와이어에 대한 연구가 주를 이룬다. 실리콘 웨이퍼 형태로 제작이 가능하기 때문에 공정상으로도 복잡하 지 않다는 장점이 있다. 그러나 용매에 분산시켜 사용하 는 0 차원과 2 차원과 달리 웨이퍼의 형태로 사용하기 때 문에 캘리포니아 대학의 Peidong Yang연구팀과 같이 이산화 티타늄과의 heterosystem을 이용한 것과 ${ }^{6}$ 같은 광 전기화학 촉매에 더욱 적합하여 광 촉매로는 잘 사용 되지 않는다. 위에 언급한 Science and Technology of China 대학의 Yujie Xiong연구팀은 나노 와이어를 이
용한 실험과 제일원리계산를 이용하여 실리콘 표면에서 의 반응을 예측했을 뿐 아니라 유일하게 실리콘을 이용 하여 산소발생을 확인하였다. 다른 실험과 달리 용매에 메탄올을 첨가하지 않고 순수한 물 만을 사용해 정공이 모든 반응에 참여하도록 하였다. 위 식 (5)에 표현된 실 리콘과 산소의 결합은 식 (8) 과 같이 다시 정공과 반응 하여 카르복실기 $(-\mathrm{OOH})$ 를 형성하게 되고 또 다시 정공 과 반응해 식 (9)와 같이 산소를 발생하게 된다. 수소발 생시는 전자 하나와 반응하여 생성되는 반면 산소발생 시 최소 3 개의 정공이 반응하여야 산소가 생성이 된다. 이러한 이유로 수소 발생량 $(4.48 \mu \mathrm{mol} /(\mathrm{g} \cdot \mathrm{hr}))$ 발생량 이 훨씬 적은 $0.91 \mu \mathrm{mol} /(\mathrm{g} \cdot \mathrm{hr})$ 값이 관측되었다.

$$
\begin{aligned}
& h^{+}+\mathrm{Si}-\mathrm{O}+\mathrm{H}_{2} \mathrm{O}=\mathrm{Si}\left(h^{+}\right)-\mathrm{O}+\mathrm{H}_{2} \mathrm{O}=\mathrm{Si}-\mathrm{OOOH}+H^{+} \\
& h^{+}+\mathrm{Si}-\mathrm{OOH}=\mathrm{Si}\left(h^{+}\right)-\mathrm{OOH}=\mathrm{Si}+\mathrm{O}_{2}+H^{+}
\end{aligned}
$$

\subsection{2차원 재료}

실리콘 나노 시트는 그래핀과 같이 독특한 전기적 인 특성과 광학적이 예상되어 많은 분야에서 폭발적으 


\section{특 집 ㅍ 이민우, 심우영†}

(a)

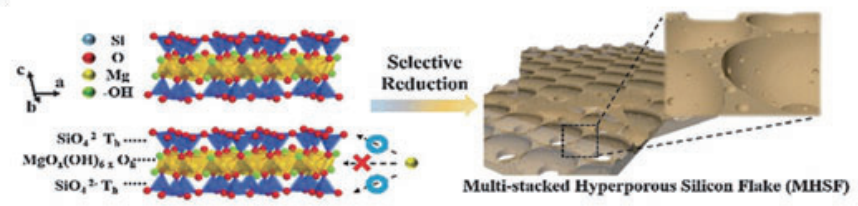

(b)

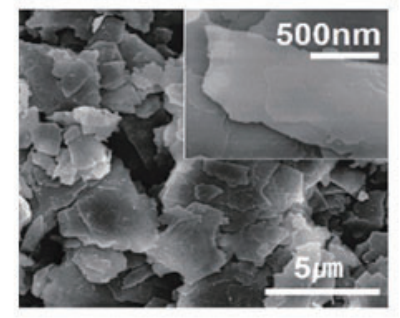

(c)

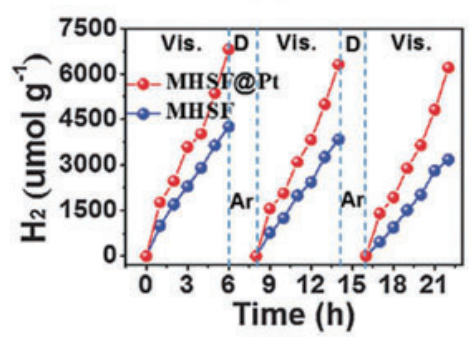

(d)

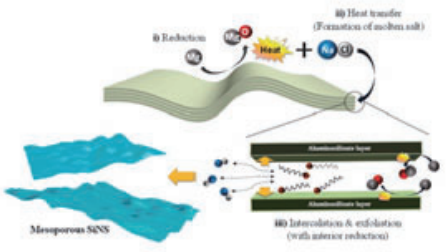

(e)

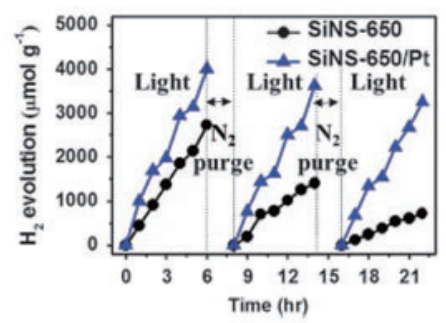

Fig. 4. 2차원 실리콘 제조방법 및 수소발생 데이터

로 연구중이다. 그럼에도 기상 증착법이 아닌 제조방법 은 많이 보고된 바가 없어 촉매로 사용할 수 있는 방법 은 매우 한정적이다. Unist대학의 이재성 교수 연구팀은 이차원물질인 Clay를 마그네슘 환원을 통해 실리콘 나 노 시트를 만드는 2가지 연구를 하였다. 첫번째는 Fig. 4 (a)에서 보듯 자연상태에서 2차원 구조를 가지는 Talc clay 물질을 사용하였다. 그 결과 다공성 물질이 생성되 어 표면적이 $188 \mathrm{~m}^{2} / \mathrm{g}$ 이고 기공 직경 $100 \mathrm{~nm}$ 이상이 대 부분이어서 그림과 같은 특이한 구조라 예상할 수 있다 7). Fig. 4 (b)에서 볼 수 있듯 주사전자현미경을 통해 판 상형인 것을 확인할 수 있었고, Fig. 4 (c)와 같이 평균 $709.51 \mu \mathrm{mol} /(\mathrm{g} \cdot \mathrm{hr})$ 의 수소 발생량이 나타났었다. 반응 시 실리콘의 표면산화로 인한 감퇴를 방기하기 위해 산 화되더라도 전자가 표면으로 이동할 수 있도록 백금 나 노 입자를 표면에 생성하였다. 그 결과 효율이 1031.62 $\mu \mathrm{mol} /(\mathrm{g} \cdot \mathrm{hr}$ )만큼 증가하는 것을 확인했다. 두번째의 경 우도 Fig. 4 (d)와 같이 자연상의 2차원물질인 MMT clay를 사용하였다 ${ }^{8)}$. 마찬가지로 마그네슘 환원을 통해 다공성 실리콘 나노 시트를 만들었고 평균 $5 \mathrm{~nm}$ 미터의 두께를 가진 표면적 $308 \mathrm{~m}^{2} / \mathrm{g}$ 임을 확인했다. Fig. 4 (e) 에 보이듯 수소 발생량이 $486 \mu \mathrm{mol} /(\mathrm{g} \cdot \mathrm{hr})$ 이고 백금 나 노 입자를 이용할 경우 $723 \mu \mathrm{mol} /(\mathrm{g} \cdot \mathrm{hr})$ 으로 증가하는
것을 확인 가능했다.

\section{3. 맺음말}

광 촉매는 에너지 기술에서의 핵심기술로 수소발생, 오 염물질제거, 유기 화합물 합성 등에 폭 넓게 적용될 전망 이다. 그 중 실리콘을 이용한 재료의 경우 넓은 광 흡수 영역, 낮은 가격 등으로 인한 장점을 바탕으로 미래에너 지산업에서 두각을 나타낼 것이 분명하다. 하지만 몇 가 지 현실적인 문제로 상용화와는 거리가 먼 연구에 그치 고 있다. 이를 해결하기 여러 방법 중 하나로 표면산화로 인한 낮은 지속성을 해결하여야 할 것이다. 특히 하이드 록실기와 광 여기된 전자의 반응으로 인한 원천적인 효 율저하에 대한 반응 메커니즘을 좀 더 명확히 규명하고 이에 따른 광 효율증대 설계 및 연구가 충분히 이루어져 야 한다. 또한 같은 광 흡수 적용사례인 태양전지와 같 이 반사되거나 투과되는 빛을 다시 이용할 수 있는 antireflection coating 및 back contact와 같은 연구가 충분 히 이루어져야 한다. 에너지 산업이 급격히 증가하고 있 는 만큼 흡광도 개선과 지속성 문제가 해결된다면 실리콘 광 촉매가 급부상할 수 있는 계기가 될 것이다. 


\section{REFERENCES}

1. Chen, Shiyou, et al. "Thermodynamic oxidation and reduction potentials of photocatalytic semiconductors in aqueous solution." Chem. Mater., 24.18, 3659-3666 (2012).

2. Liu, Dong, et al. "The nature of photocatalytic "water splitting" on silicon nanowires." Angew. Chem., Int. Ed. 54.10, 2980-2985 (2015).

3. Erogbogbo, Folarin, et al. "On-demand hydrogen generation using nanosilicon: splitting water without light, heat, or electricity." Nano Lett., 13.2, 451-456 (2013).

4. Dai, Fang, et al. "Bottom-up synthesis of high surface area mesoporous crystalline silicon and evaluation of its hydrogen evolution performance." Nat. Commun., 5.1, 1-11 (2014).

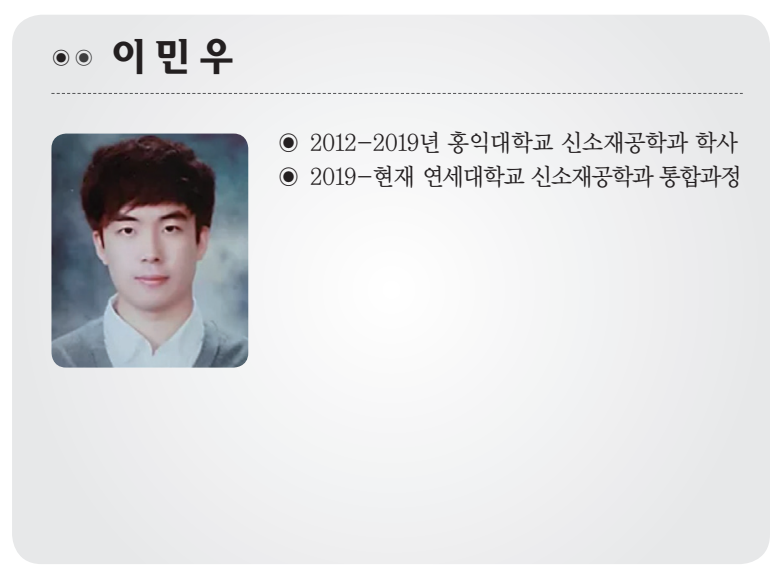

5. Song, Hongguang, et al. "Highly crystalline mesoporous silicon spheres for efficient visible photocatalytic hydrogen evolution." ChemNanoMat, 3.1, 22-26 (2017).

6. Liu, Chong, et al. "A fully integrated nanosystem of semiconductor nanowires for direct solar water splitting." Nano Lett., 13.6, 2989-2992 (2013).

7. Jang, Youn Jeong, et al. “A multi-stacked hyperporous silicon flake for highly active solar hydrogen production." Chem. Commun., 52.67, 10221-10224 (2016).

8. Ryu, Jaegeon, et al. "All-in-one synthesis of mesoporous silicon nanosheets from natural clay and their applicability to hydrogen evolution.” NPG Asia Mater., 8.3, e248-e248 (2016).

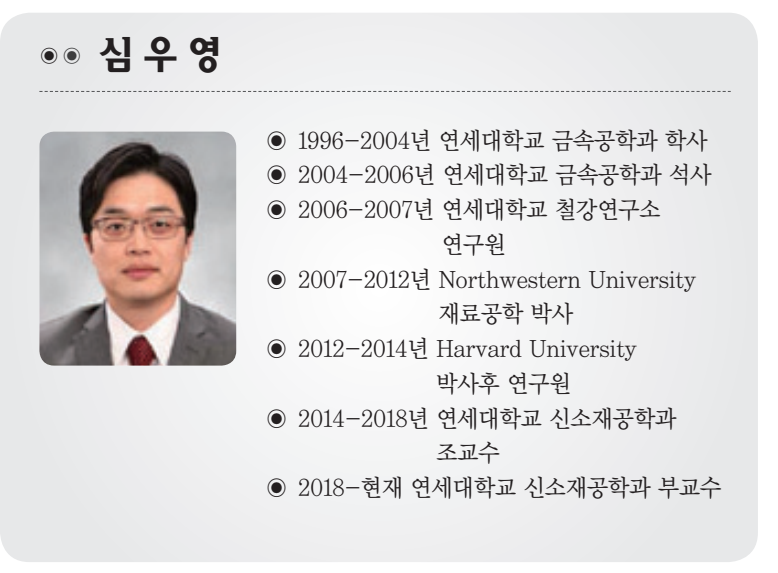

